Check for updates

Cite this: RSC Adv., 2019, 9, 24852

\title{
Nitrogen-doped fluorescent carbon dots used for the imaging and tracing of different cancer cells
}

\author{
Tinghua Yan, ${ }^{a}$ Wang Zhong, ${ }^{a}$ Ruiming Yu, ${ }^{\mathrm{b}}$ Gao Yi, ${ }^{\mathrm{b}}$ Zeping Liu, ${ }^{\mathrm{b}}$ Lihong Liu, \\ Xinxing Wang (DD ${ }^{* d}$ and Jinhua Jiang ${ }^{* c}$
}

Here, we report the synthesis of nitrogen-doped fluorescent carbon (C) dots using a one-pot hydrothermal method. Transmission electron microscopy results reveal that the particle size of the nitrogen-doped Cdots is very small, with an average diameter of $4.6 \mathrm{~nm}$. After being kept in water for 10 days, the nitrogen-doped $\mathrm{C}$-dots can still dissolve well in the water, showing good stability and compatibility in aqueous solution. The fluorescence spectra show that the nitrogen-doped C-dots exhibit emissiontunable color from blue to green upon excitation from 230 to $520 \mathrm{~nm}$. Cell tests show that the C-dots are low in cytotoxicity and can be used for imaging, detecting and tracing between hepatoma and HeLa cells, because hepatoma and HeLa cells show different sensitivity to different fluorescent colors pumped at different excitation wavelengths.

Received 28th April 2019 Accepted 31st May 2019

DOI: 10.1039/c9ra03170g

rsc.li/rsc-advances dimensional (2D) materials, ${ }^{24-26}$ mechano-optical converters, ${ }^{27,28}$ down-conversion, ${ }^{29-31}$ up-conversion, ${ }^{32-35}$ and afterglow particles, ${ }^{36-38}$ and metal-organic frameworks (MOFs). ${ }^{39,40}$ Most of them, however, suffer from either high cytotoxicity and cost (i.e. organic dyes and Cd-related QDs), a large particle size (usually micro-size, i.e. mechano-optical converters), single emission color (i.e. trivalent rare earthdoped phosphor materials), or ultrahigh molecular weight and complicated synthesis processes (i.e. MOFs), which are undesirable for biological imaging purposes.

Unlike the above fluorescent materials, carbon dots (C-dots) are a type of heavy-metal-free nanomaterial. ${ }^{\mathbf{4 1 - 4 3}}$ They have been found to have a variety of advantages that other materials do not have, for example, excitation-dependent tunable-emissions, ${ }^{44}$ raw materials with low cost, ${ }^{45}$ small particle size,${ }^{46}$ and many facile synthesis strategies. ${ }^{17}$ Moreover, C-dots doped with other heteroatoms (e.g. nitrogen, ${ }^{44}$ sulfur, ${ }^{47}$ and boron ${ }^{48}$ ) show improved optical and electronic properties, allowing the C-dots to have broader application opportunities compared to pure C-dots.

In this work, we fabricated and reported a type of nitrogendoped fluorescent C-dots using a one-pot hydrothermal method. In order to characterize the phase-purity, structural information and fluorescence properties of the nitrogen-doped C-dots, various techniques, such as X-ray diffraction (XRD), transmission electron microscopy (TEM), and fluorescence spectroscopy, were carried out. As a result, we found that the Cdots possess the advantages of being small in size, rich nitrogen content $(28.56 \%)$, excitation-dependent tunable emissions, low cytotoxicity and good stability in water. Typically, our biological application revealed that this type of C-dots could allow us to trace, detect, localize, and distinguish between hepatoma and HeLa cells when the two cells were mixed with each other.

\footnotetext{
${ }^{a}$ Shanghai University of Medicine \& Health Sciences, Affiliated Sixth People's Hospital South Campus, Shanghai, China

${ }^{b}$ Department of Oncology, Humanity Hospital of Longyan City, Longyan, China 'Department of Oncology Interventional Therapy, Renji Hospital, School of Medicine, Shanghai Jiao Tong University, Shanghai, China. E-mail: scarli8880@126.com ${ }^{d}$ Department of Environmental Engineering, Zhejiang Normal University, Hangzhou 310058, China. E-mail: superfly56@126.com

${ }^{e}$ State Key Laboratory of Environmental Chemistry and Ecotoxicology, Chinese Academy of Sciences (CAS), Beijing, China
}

\footnotetext{
-
} 
Table 1 Nitrogen content of the obtained C-dots achieved using different content ratios $(R)$ of ethylenediamine and anhydrous citric acid at different temperatures

\begin{tabular}{|c|c|c|c|c|}
\hline & Ethylenediamine/mL & Anhydrous citric acid/g & Temperature $/{ }^{\circ} \mathrm{C}$ & $\mathrm{N}$ content/\% \\
\hline \multirow{8}{*}{ 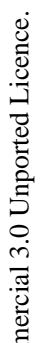 } & 40 & 1 & 140 & 3.75 \\
\hline & 40 & 3 & 160 & 10.21 \\
\hline & 40 & 5 & 180 & 28.56 \\
\hline & 40 & 7 & 200 & 24.38 \\
\hline & 40 & 9 & 240 & 19.59 \\
\hline & 40 & 5 & 140 & 21.60 \\
\hline & 40 & 5 & 160 & 22.67 \\
\hline & 40 & 5 & 200 & 26.74 \\
\hline
\end{tabular}

\section{Experimental section}

\subsection{Synthesis details}

We prepared nitrogen doped C-dots using a one-pot hydrothermal method. ${ }^{49-51}$ We first used $40.0 \mathrm{~mL}$ of distilled water to dissolve ethylenediamine and anhydrous citric acid and then transferred the dissolved solution into a $100 \mathrm{~mL}$ Teflon-lined autoclave, where the amounts of ethylenediamine and anhydrous citric acid used can be found in Table 1. After being treated at different temperatures (Table 1 ) for $2 \mathrm{~h}$ and then subjected to a dialysis membrane (cut-off $M_{\mathrm{n}}: 3.0 \mathrm{kDa}$ ) at room temperature for $48 \mathrm{~h}$, the target brown colored nitrogen $\mathrm{C}$-dots were freeze-dried under vacuum.

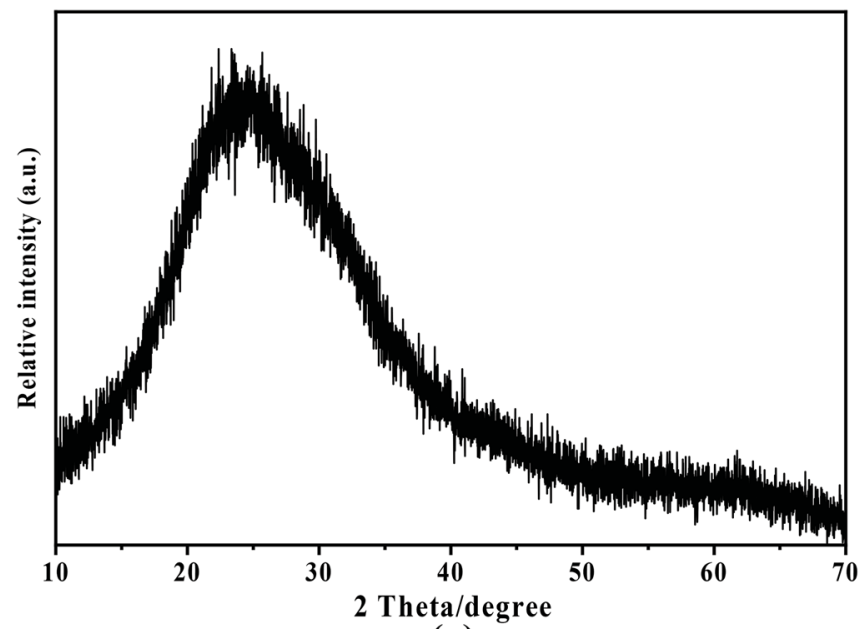

(a)

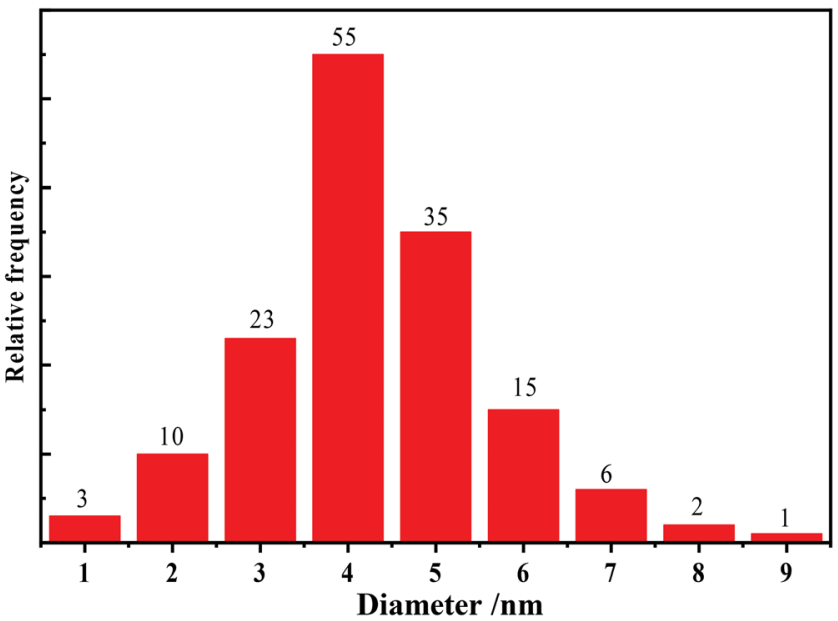

(c)

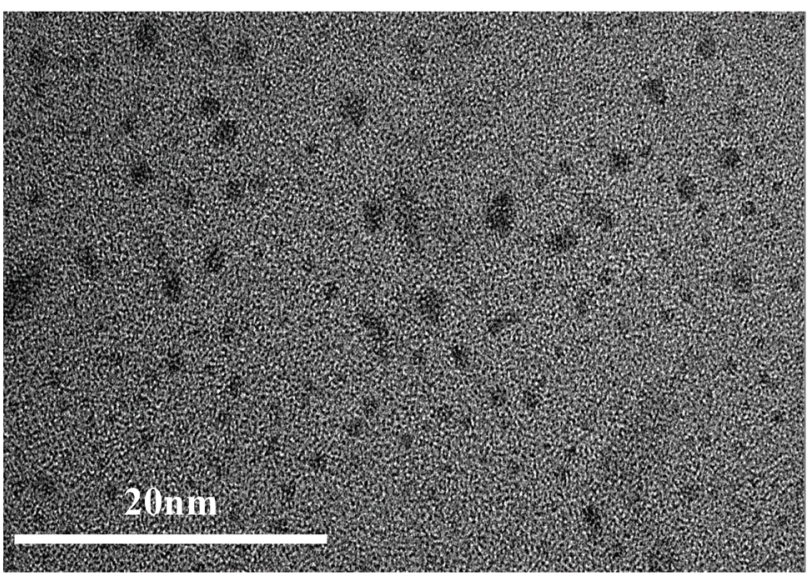

TEM image

(b)
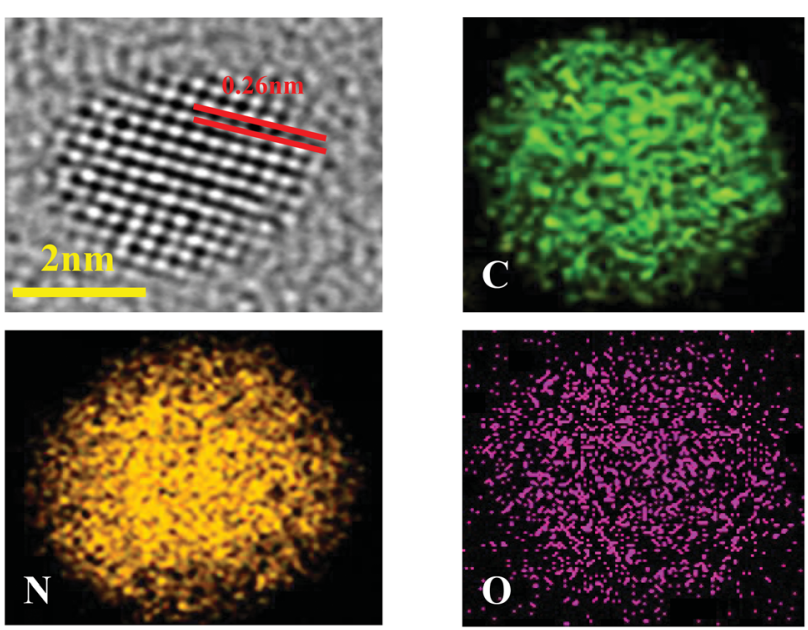

(d)

Fig. 1 (a) XRD pattern, (b) TEM image, (c) size distribution, (d) high-resolution TEM image and elemental mapping of the as-prepared nitrogen Cdots. 


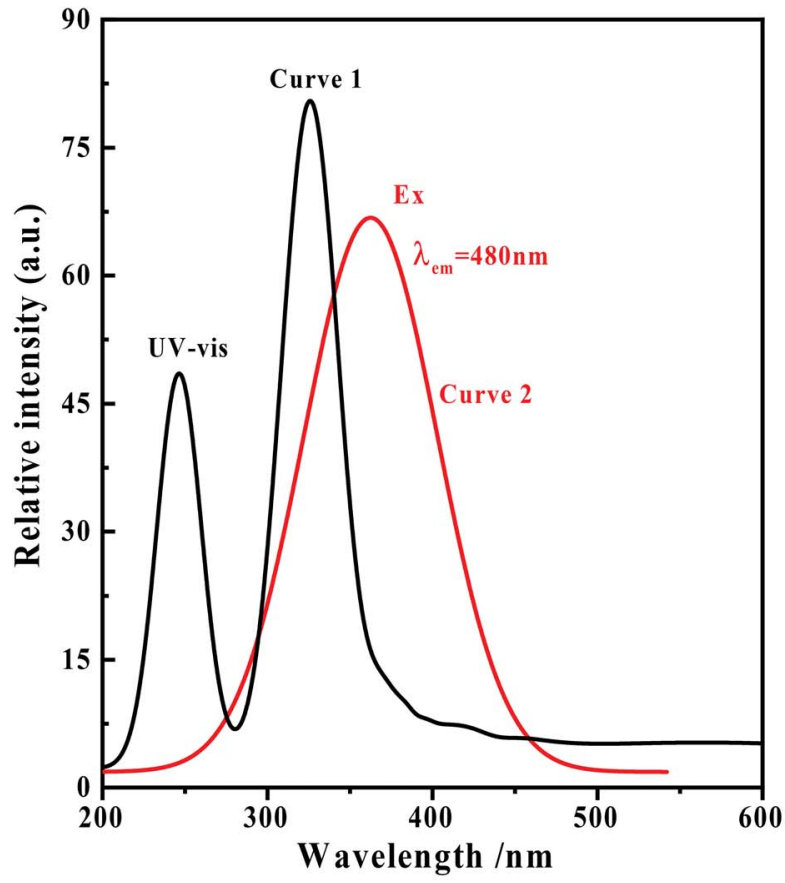

(a)

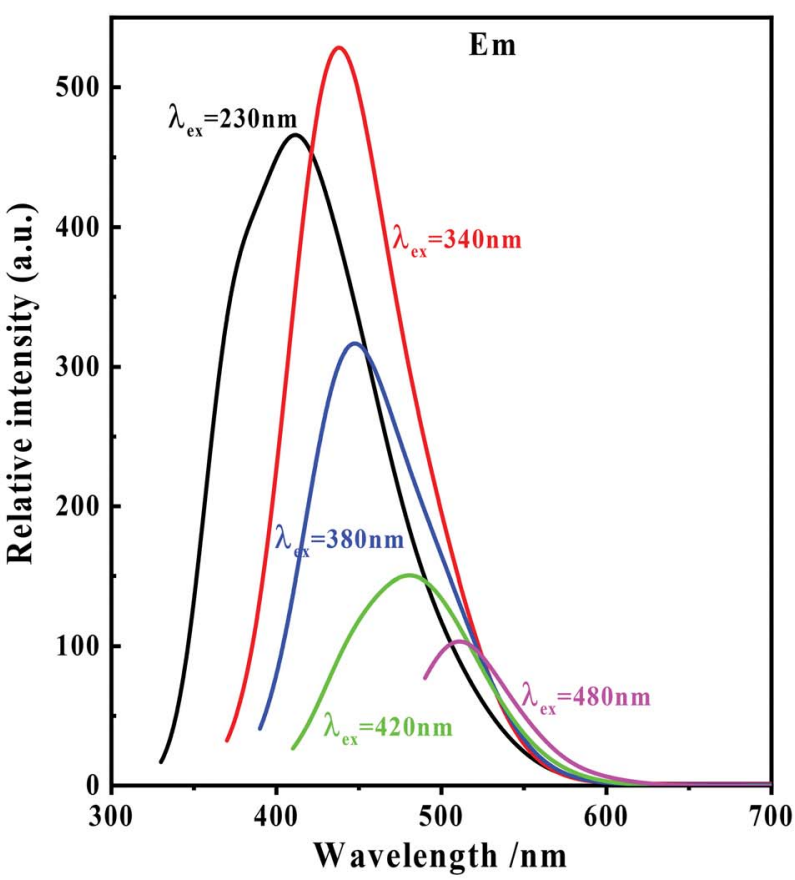

(b)

Fig. 2 (a) UV-vis absorption (curve 1) and excitation spectra (curve 2) of the nitrogen C-dots; (b) fluorescence spectra of the nitrogen C-dots upon excitation in the range of $230-480 \mathrm{~nm}$.

\subsection{Characterization details}

The X-ray diffraction (XRD) of the nitrogen C-dots was recorded on a Bruker diffractometer utilizing $\mathrm{Cu} \mathrm{K} \alpha$ as the radiation source $(\lambda=1.5418 \AA$ ). The ultraviolet-visible (UV-vis) absorption and fluorescence spectra were recorded using a PerkinElmer Lambda 25 spectrophotometer and FLS920P Edinburgh Analytical Instrument (Edinburgh Instruments), respectively. Transmission electron microscope (TEM) images were collected

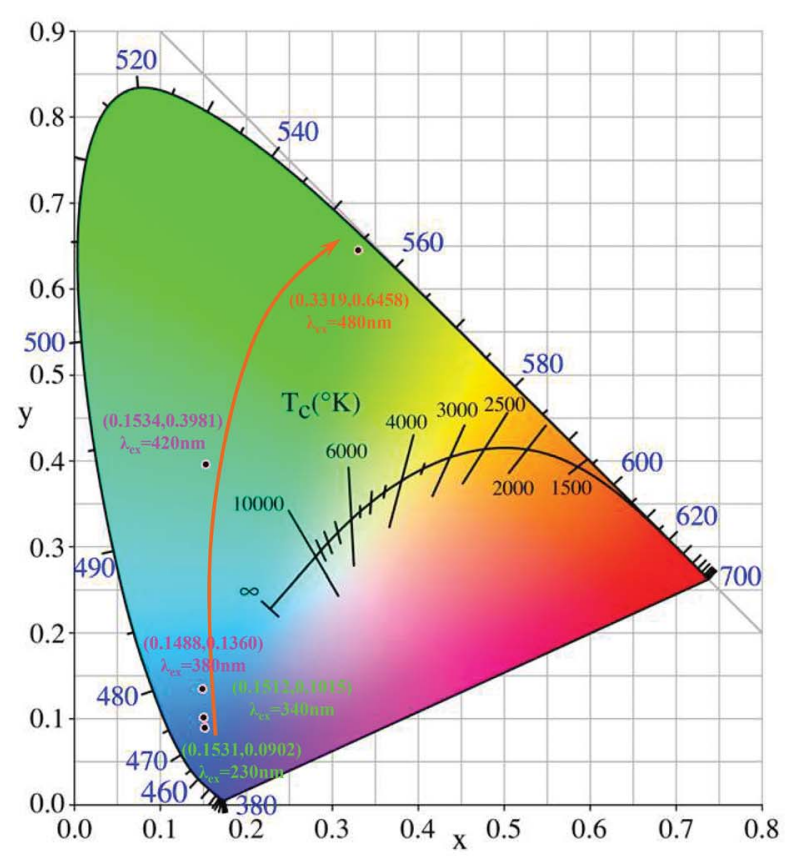

(a)

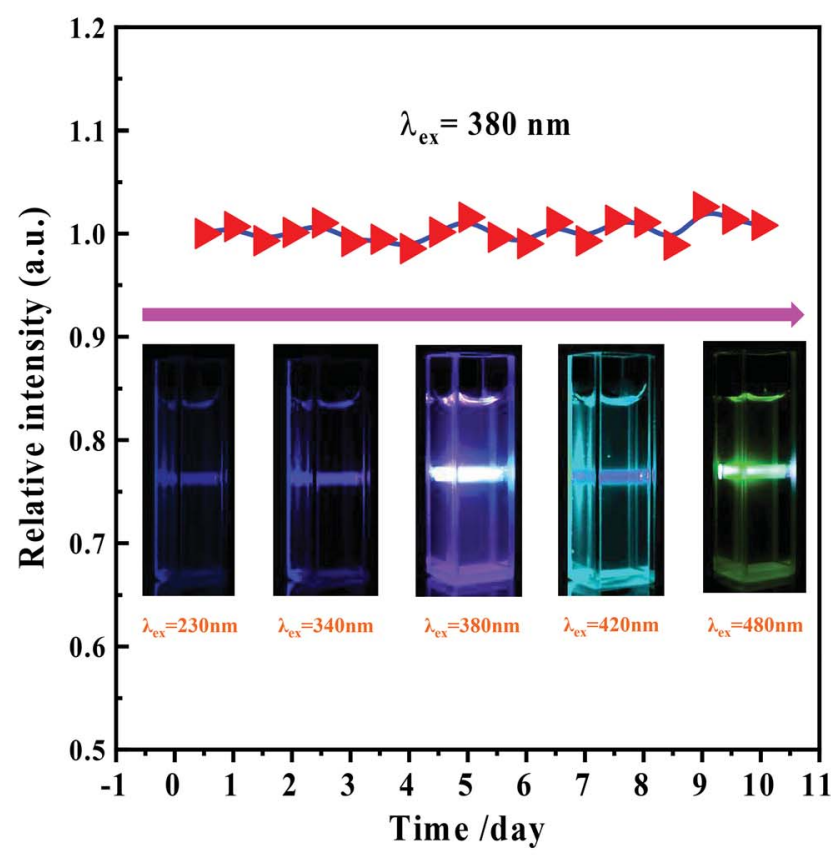

(b)

Fig. 3 (a) CIE chromaticity coordinates derived from the emission spectra in Fig. 2(b); (b) dependence of the emission intensity in terms of days $\left(\lambda_{\mathrm{ex}}=380 \mathrm{~nm}\right)$ and digital fluorescent colors recorded by exciting with different wavelengths of light (inset). 


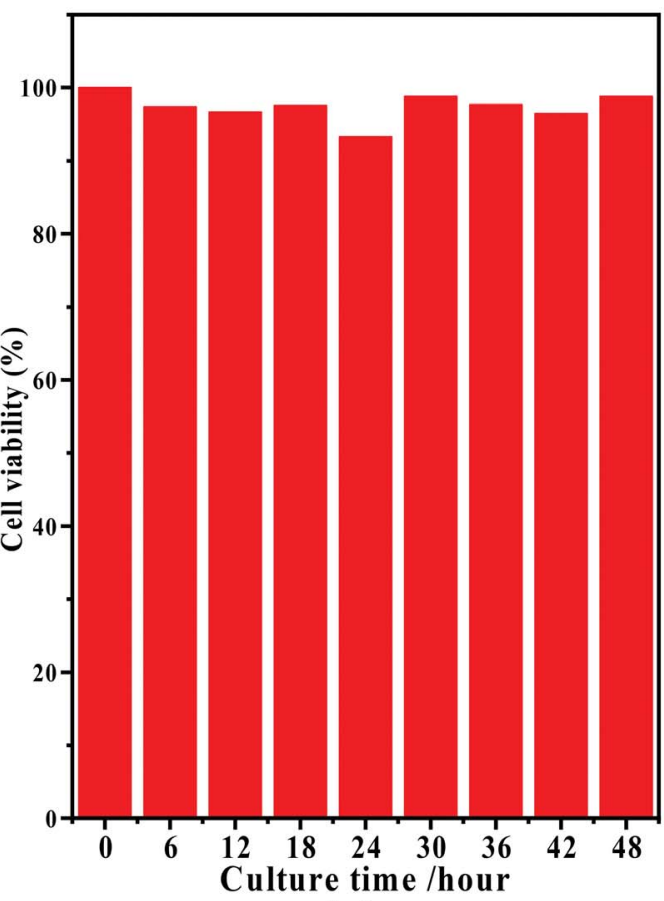

(a)

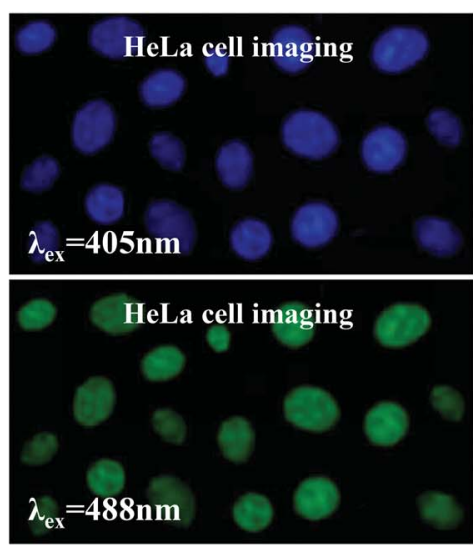

(b)

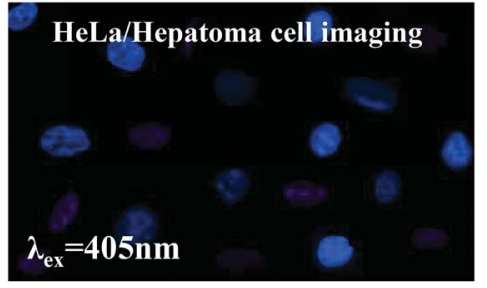

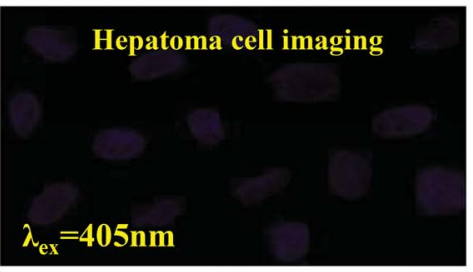

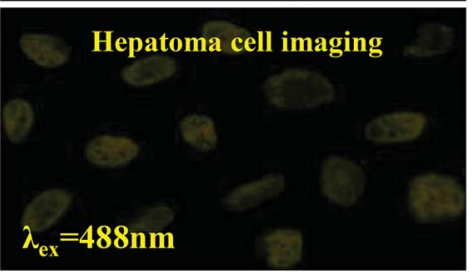

(c)

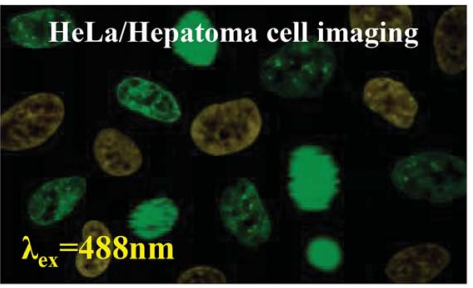

(d)

Fig. 4 (a) Viability of HeLa cells after being cultured with $1.0 \mathrm{mg} \mathrm{mL}^{-1}$ of $\mathrm{C}$-dots for $48 \mathrm{~h}$; (b) imaging patterns of HeLa cells upon excitation at 405 and $488 \mathrm{~nm}$; (c) imaging patterns of hepatoma cells upon excitation at 405 and $488 \mathrm{~nm}$; and (d) imaging patterns of HeLa-hepatoma cells upon excitation at 405 and $488 \mathrm{~nm}$.

by a JEM-2100F (JEOL, Japan) instrument. The cell imaging was performed on a confocal microscopy equipped with 405 and $488 \mathrm{~nm}$ lasers.

\section{Results and discussion}

\subsection{Structural analysis}

The XRD pattern of the as-prepared nitrogen C-dots is shown in Fig. 1(a). A broad diffraction peak located at $23.85^{\circ}$ is observable. This peak can be ascribed to the (002) lattice spacing that results from the diffraction of disordered carbon atoms, which can be seen in studies on other reported carbon-based materials. ${ }^{41-50}$ The related TEM image reveals that the as-obtained Cdots are spherical dots (Fig. 1(b)) with a narrow size distribution (Fig. 1(c)). The average size of the nitrogen C-dots is $\sim 4.6 \mathrm{~nm}$. The high-resolution TEM image shows that the lattice spacing is $0.26 \mathrm{~nm}$ (see Fig. 1(d)), which is associated with the (100) facet of $\mathrm{sp}^{2}$ graphitic carbon. ${ }^{51,52}$ The elemental mapping (see Fig. 1(d)), recording from one particle of the nitrogen C-dots, confirms that the C-dots consist of $\mathrm{N}, \mathrm{C}$, and $\mathrm{O}$ elements. The EDS analysis shows that the maximum nitrogen content is $28.56 \%$, which is related to the C-dots being prepared with $40 \mathrm{~mL}$ of ethylenediamine and $5.0 \mathrm{~g}$ of anhydrous citric acid at $180{ }^{\circ} \mathrm{C}$. Such nitrogen content is higher than other nitrogen contents reported in previous works, such as, $25.1 \% \mathrm{~N}$ content in N,S-doped C-dots ${ }^{53}$ and $18 \% \mathrm{~N}$ content in N,S-doped C-dots. ${ }^{54}$ Such a high nitrogen content ensures that the nitrogen C-dots have good solubility in water.

\subsection{UV-vis absorption and fluorescence spectral analysis}

The UV-vis absorption curve of the nitrogen C-dots is shown in Fig. 2(a) (curve 1). In the figure, two absorption bands at around 244 and $323 \mathrm{~nm}$, which are ascribed to the $\pi-\pi^{*}$ transitions of the carbonyl group $(\mathrm{CC} / \mathrm{CO})$ and $n-\pi^{*}$ transitions of the amine moiety, ${ }^{51-54}$ are observable within the range of 200-400 $\mathrm{nm}$. The absorption tail terminates at about $520 \mathrm{~nm}$. In this case, we recorded the fluorescence spectra of nitrogen C-dots upon excitation in the range of 230-500 nm. As depicted in Fig. 2(b), as the excitation wavelength increases from 230 to $500 \mathrm{~nm}$, the nitrogen C-dots show a regular shift in emission positions. Such excitation-dependent tunable fluorescence further results in a regular change in the Commission International d'Eclairage (CIE) chromaticity coordinates and tunable emission colors from blue to green (Fig. 3(a)). Moreover, the nitrogen C-dots, after being placed in water for 10 days, still exhibited bright fluorescence upon irradiation at $365 \mathrm{~nm}$. The emission intensity is comparable to the initial emission intensity upon excitation at $365 \mathrm{~nm}$ (Fig. 3(b)). This indicates that this type of nitrogen C-dots holds excellent stability in aqueous solution. As shown in Fig. 2(a) (curve 2), the nitrogen C-dots exhibited one excitation band, with the maximum intensity at $380 \mathrm{~nm}$, which is the reason why we use the excitation wavelength of $380 \mathrm{~nm}$ to record the emission intensity of Fig. 3(b).

\subsection{Biological application}

Based upon the florescence of Fig. 3(b) (inset), the C-dots feature a variety of emission colors upon different excitation 
wavelengths. Typically, when considering semiconductor 405 and $488 \mathrm{~nm}$ lasers, we believe they can be used for the imaging of cells. Moreover, enlightened by the results reported by $\mathrm{Zhu}^{55}$ and Zhou et al., ${ }^{56,57}$ it was found that different cells can exhibit different responses in their sensitivity to different fluorescence, which could allow us to use the nitrogen C-dots to trace, detect and distinguish between a given type of cell from other cells. Prior to the related experiments, we first verified the toxicity of the C-dots using HeLa cells, through mixing the C-dots and HeLa cells and then monitored the survival viability of the HeLa cells. As shown in Fig. 4(a), we observed that HeLa cells after being cultured with $1.0 \mathrm{mg} \mathrm{mL^{-1 }}$ of C-dots for $48 \mathrm{~h}$ exhibit viability analogous to the comparative HeLa cells without Cdots. The viability of the HeLa cells after being cultured for $48 \mathrm{~h}$ remained at more than $97 \%$, indicating that the nitrogen C-dots exhibit low cytotoxicity and thus can be used for cell imaging. As revealed in Fig. 4(b), upon excitation at 405 and $488 \mathrm{~nm}$, two colors, as shown in the digital images, are observable in the C-dot-stained HeLa cells. The results in Fig. 4(b) reveal that the nitrogen C-dots successfully entered into the membrane and cytoplasmic area of the HeLa cells. Furthermore, such fluorescent colors are also suitable for imaging other cells such as hepatoma cells (Fig. 4(c)). However, the hepatoma cells show different imaging colors from those of the HeLa cells, where the imaging colors excited at 405 and $488 \mathrm{~nm}$ are purple and yellow, respectively. In view of this, we proposed to distinguish between hepatoma and HeLa cells when the two types of cells were mixed with each other. We first mixed $10 \mu \mathrm{L}$ of HeLa cells and $10 \mu \mathrm{L}$ of hepatoma cells and then injected $10 \mu \mathrm{L}$ of $1.0 \mathrm{mg} \mathrm{L}{ }^{-1} \mathrm{C}$-dots into the mixed cells. As shown in Fig. 4(d), we observed two types of different fluorescent colors that correspond to the two types of cells. More specifically, upon excitation at 405 and $488 \mathrm{~nm}$, the C-dotcultured HeLa cells exhibit blue and green colors, which are the same as shown in Fig. 4(b). However, the hepatoma cells exhibit purple and yellow colors analogous to those shown in Fig. 4(c). Obviously, we have used the nitrogen C-dots as a type of imaging probe technique to trace, detect and distinguish between hepatoma and HeLa cells based upon the different sensitivities of the different cells to different fluorescence.

\section{Conclusions and outlook}

In this work, nitrogen rich C-dots were prepared using a one-pot hydrothermal method. We revealed that the maximum nitrogen content of the C-dots was as high as $28.56 \%$. With an increase in the excitation wavelength from 230 to $520 \mathrm{~nm}$, excitationdependent fluorescence from blue to green was observable for the nitrogen rich C-dots. With the features of being small in size, having good stability in water and low cytotoxicity, as well as excitation-dependent tunable fluorescence, we found that the HeLa cells after being cultured with C-dots exhibited blue and yellow fluorescence upon excitation at 405 and $488 \mathrm{~nm}$, analogous to the colors exhibited in aqueous solution, respectively. Moreover, based upon the behavior that involves the different sensitivities of different cells to different fluorescence, by using the C-dots, we were able to trace, detect and distinguish between hepatoma and HeLa cells.

Actually, the underlying reasons for the above observation after an in-depth consideration are very complicated, which can be related to a lot of potential mechanisms that can lead to the change of fluorescent colors in the as-obtained carbon dots. On the one hand, such a difference may be due to the unique protein properties of each of the cells and their different extent of C-dot accumulation. The C-dots exhibit different colors when they have different accumulations. In addition, this may also be because the proteins of the different cells are sensitive to their surrounding environments. Furthermore, since the particle size of the C-dots can influence the fluorescent colors. A smaller size is usually related to blue fluorescence, while a bigger size is related to red fluorescence. In this case, we also deduced that different types of cells may absorb different sizes of C-dots, leading to the different fluorescence of the cells. Although we have only so far demonstrated that two types of cells can exhibit these results when mixed together, we believe that there is the potential for other types of cells to also exhibit this behavior. This is a new, yet exciting, observation, which needs further study in the future in order to understand the underlying reasons behind this behavior. This work shows that C-dots can not only be used for biomedical imaging, but can also be used as an effective, low cost and non-invasive detection method to trace and distinguish between hepatoma and HeLa cells.

\section{Conflicts of interest}

The authors declare that they have no conflicts of interest with the contents of this article.

\section{References}

1 L. Kelland, Nat. Rev. Cancer, 2007, 7, 573-584.

2 K. H. Bae, M. Park, M. J. Do, N. Lee, J. H Ryu, G. W. Kim, C. Kim, T. G. Park and T. Hyeon, ACS Nano, 2012, 6, 52665273.

3 T. Kobayashi, Biotechnol. J., 2011, 61342-61347.

4 Z. J. Zhang, J. Wang and C. Y. Chen, Adv. Mater., 2013, 25, 3869-3880.

5 Z. Xiao, C. Ji, J. Shi, E. M. Pridgen, J. Frieder, J. Wu and O. C. Farokhzad, Angew. Chem., Int. Ed., 2012, 51, 1185311857.

6 M. Yu, F. Guo, F. Tan and N. Li, J. Controlled Release, 2015, 215, 91-100.

7 A. Hervault and N. T. K. Thanh, Nanoscale, 2014, 6, 1155311573.

8 P. Pradhan, J. Giri, F. Rieken, C. Koch, O. Mykhaylyk, M. Döblinger, R. Banerjee, D. Bahadur and C. Plank, J. Controlled Release, 2010, 142, 108-121.

9 R. R. Love, H. Leventhal, D. V. Easterling and D. R. Nerenz, Cancer, 1989, 63, 604-612.

10 A. H. Partridge, H. J. Burstein and E. P. Winer, JNCI Monogr., 2001, 2001, 135-142. 
11 A. I. Buizer, L. M. J. de Sonneville, M. M. van den HeuvelEibrink and A. J. P. Veerman, Pediatr. Blood Cancer, 2005, 42, 281.

12 T. S. Hauck, T. L. Jennings, T. Yatsenko, J. C. Kumaradas and W. C. W. Chan, Adv. Mater., 2008, 20, 3832-3838.

13 L. Yuan, W. Y. Lin, K. B. Zheng, L. W. He and W. M. Huang, Chem. Soc. Rev., 2013, 42, 622-661.

14 X. Y. Zhang, X. Q. Zhang, B. Yang, M. Y. Liu, W. Y. Liu, Y. W. Chen and Y. Wei, Polym. Chem., 2013, 4, 4317-4321.

15 U. Resch-Genger, M. Grabolle, S. Cavaliere-Jaricot, R. Nitschke and T. Nann, Nat. Methods, 2008, 5, 763-775.

16 Z. M. Tao, G. S. Hong, C. Shinji, C. X. Chen, S. Diao, A. L. Antaris, B. Zhang, Y. P. Zou and H. J. Dai, Angew. Chem., Int. Ed., 2013, 52, 13002-13006.

17 A. W. Wang, F. W. Kang, Z. G. Wang, Q. G. Shao, Z. Li, G. Y. Zhu, J. Lu and Y. Y. Li, Adv. Sustainable Syst., 2019, 3, 1800132.

18 I. L. Medintz, H. T. Uyeda, E. R. Goldman and H. Mattoussi, Nat. Mater., 2005, 4, 435-446.

19 J. K. Jaiswal, H. Mattoussi, J. M. Mauro and S. M. Simon, Nat. Biotechnol., 2003, 21, 47-51.

20 A. M. Smith, H. W. Duan, A. M. Mohs and S. M. Nie, Adv. Drug Delivery Rev., 2008, 60, 1226-1240.

21 C. F Wu, B. Bull, C. Szymanski, K. Christensen and J. McNeill, ACS Nano, 2008, 2, 2415-2423.

22 K. Y. Pu, A. J. Shuhendler, J. V. Jokerst, J. G. Mei, S. S. Gambhir, Z. N. Bao and J. H. Rao, Nat. Nanotechnol., 2014, 9, 233-239.

23 K. Li and B. Liu, Chem. Soc. Rev., 2014, 43, 6570-6597.

24 S. A. Jones, S.-H. Shim, J. He and X. W. Zhuang, Nat. Methods, 2011, 8, 499-505.

25 V. Emiliani, D. Sanvitto and M. Tramier, Appl. Phys. Lett., 2003, 83, 2471.

26 L. H. V. Wang, X. M. Zhao, H. T. Sun and G. Ku, Rev. Sci. Instrum., 1999, 70, 3744.

27 N. Terasaki, H. W. Zhang, H. Yamada and C.-N. Xu, Chem. Commun., 2011, 47, 8034-8036.

28 C. M. Lau, X. W. Xu and K. W. Kwok, Appl. Surf. Sci., 2015, 336, 314-320.

29 Y. T. Zhong, Z. R. Ma, S. J. Zhu, J. Y. Yue, M. X. Zhang, A. L. Antaris, J. Yuan, R. Cui, H. Wan, Y. Zhou, W. Z. Wang, N. F. Huang, J. Luo, Z. Y. Hu and H. J. Dai, Nat. Commun., 2017, 8, 737.

30 H. F. Dong, S. S. Tang, Y. S. Hao, H. Z. Yu, W. H. Dai, G. F. Zhao, Y. Cao, H. T. Lu, X. J. Zhang and H. X. Ju, ACS Appl. Mater. Interfaces, 2016, 8, 3107-3114.

31 G. Brida, M. Genovese and I. R. Berchera, Nat. Photonics, 2010, 4, 227-230.

32 L. L. Li, P. W. Wu, K. Hwang and Y. Lu, J. Am. Chem. Soc., 2013, 135, 2411-2414.

33 M. X. Yu, F. Y. Li, Z. G. Chen, H. Hu, C. Zhan, H. Yang and C. H. Huang, Anal. Chem., 2019, 81, 930-935.

34 H. C. Lu, G. S. Yi, S. Y. Zhao, D. P. Chen, L.-H. Guo and J. Cheng, J. Mater. Chem., 2004, 14, 1336-1341.
35 F. W. Kang, J. J. He, T. Y. Sun, Z. Y. Bao, F. Wang and D. Y. Lei, Adv. Funct. Mater., 2017, 27, 1701842.

36 Q. Q. Miao, C. Xie, X. Zhen, Y. Lyu, H. W. Duan, X. G. Liu, J. V. Jokerst and K. Y. Pu, Nat. Biotechnol., 2017, 35, 11021110.

37 C. Xie, X. Zhen, Q. Q. Miao, Y. Lyu and K. Y. Pu, Adv. Mater., 2018, 30, 1801331.

38 X. Zhen, Y. Tao, Z. F. An, P. Chen, C. J. Xu, R. F. Chen, W. Huang and K. Y. Pu, Adv. Mater., 2017, 29, 1606665.

39 P. Horcajada, T. Chalati, C. Serre, B. Gillet, C. Sebrie, T. Baati, J. F. Eubank, D. Heurtaux, P. Clayette, C. Kreuz, J.-S. Chang, Y. K. Hwang, V. Marsaud, P.-N. Bories, L. Cynober, S. Gil, G. Férey, P. Couvreur and R. Gref, Nat. Mater., 2010, 9, 172-178.

40 K. M. L. Taylar, A. Jin and W. B. Lin, Angew. Chem., Int. Ed., 2008, 47, 7722-7725.

41 A. W. Wang, Y.-L. Hou, F. W. Kang, F. C. Lyu, Y. Xiong, W.-C. Chen, C.-S. Lee, Z. T. Xu, A. L. Rogach, J. Lu and Y. Y. Li, J. Mater. Chem. C, 2019, 7, 2207.

42 Z. N. Tan, Y. Zhang, C. Xie, H. P. Su, J. Liu, C. F. Zhang, N. Dellas, S. E. Mohney, Y. Q. Wang, J. K. Wang and J. Xu, Adv. Mater., 2011, 23, 3553-3558.

43 C. X. Wang, Z. Z. Xu, H. Cheng, H. H. Lin, M. G. Humphrey and C. Zhang, Carbon, 2015, 82, 87-95.

44 D. Qu, M. Zheng, J. Li, Z. G. Xie and Z. C. Sun, Light: Sci. Appl., 2015, 4, e364.

45 K. Jiang, L. Zhang, J. F. Lu, C. X. Xu, C. Z. Cai and H. W. Lin, Angew. Chem., Int. Ed., 2016, 55, 7231-7235.

46 K. Jiang, S. Sun, L. Zhang, Y. Lu, A. G. Wu, C. Z. Cai and H. W. Lin, Angew. Chem., Int. Ed., 2015, 54, 5360-5363.

47 Y. Q. Dong, H. C. Pang, H. B. Yang, C. X. Guo, J. W. Shao, Y. W. Chi, C. M. Li and T. Yu, Angew. Chem., Int. Ed., 2013, 52, 7800-7804.

48 H. L. Fei, R. Q. Ye, G. Ye, Y. J. Gong, Z. W. Peng, X. J. Fan, E. L. G. Samuel, P. M. Ajayan and J. M. Tour, ACS Nano, 2014, 8, 10837-10843.

49 T. Tian, Y. He, Y. L. Ge and G. W. Song, Sens. Actuators, B, 2017, 240, 1265-1271.

50 W.-J. Niu, Y. Li, R.-H. Zhu, S. Shan, Y.-R. Fan and X.-J. Zhang, Sens. Actuators, B, 2015, 218, 229-236.

51 H. Ming, Z. Ma, Y. Liu, K. M. Pan, H. Yu, F. Wang and Z. H. Kang, Dalton Trans., 2012, 41, 9526-9531.

52 C. J. Reckmeier, J. Schneider, A. S. Susha and A. L. Rogach, Opt. Express, 2016, 2, A312-A340.

53 D. Sun, R. Ban, P.-H. Zhang, G.-H. Wu, J.-R. Zhang and J.-J. Zhu, Carbon, 2013, 64, 424-434.

54 S. J. Zhao, M. H. Lan, X. Y. Zhu, H. T. Xue, T.-W. Ng, X. M. Meng, C.-S. Lee, P. F. Wang and W. J. Zhang, ACS Appl. Mater. Interfaces, 2015, 7, 17054-17060.

55 P. C. Zhu, D. D. Lyu, P. K. Shen and X. X. Wang, J. Lumin., 2019, 207, 620-625.

56 K. Zhou, Y. Zhang, Z. N. Xia and W. L. Wei, Nanotechnology, 2016, 27, 275101.

57 R. J. Liu, L. L. Zhang, Y. Y. Chen, Z. R. Huang, Y. Huang and S. L. Zhao, Anal. Chem., 2018, 90, 4452-4460. 